\title{
A PRODUCCÃO CIENTÍFICA SOBRE GESTÃO DEMOCRÁTICA NAS ESCOLAS PARAENSES
}

\author{
SCIENTIFIC PRODUCTION ON DEMOCRATIC \\ MANAGEMENT IN PARÁ STATE SCHOOLS \\ LA PRODUCCIÓN CIENTÍFICA SOBRE GESTIÓN
DEMOCRÁTICA EN LAS ESCUELAS PARAENSE
}

\author{
LARISSA MOURA LisboA BeCKeR ${ }^{\text {I }}$ \\ Maria de Fátima Matos de SouZA II \\ Renato Pinheiro Da Costa ${ }^{\text {III }}$ \\ ${ }^{\text {I }}$ Universidade Federal do Pará (UFPA), Pará/PA-Brasil \\ II Universidade Federal do Pará (UFPA), Pará/PA-Brasil \\ IIIUniversidade Federal do Pará (UFPA), Pará/PA-Brasil
}

RESUMo Este trabalho teve por objetivo analisar os princípios da gestão democrática nas escolas paraenses, a partir das dissertações e teses defendidas nos Programas de Pós-Graduação em Educação das Universidades públicas paraenses. O levantamento bibliográfico foi realizado no Banco de Teses e Dissertações do portal da CAPES. Identificou-se um conjunto de 12 trabalhos de mestrado e doutorado que examinam a problemática da gestão democrática na escola paraense. Com base na leitura dos resumos, foi possível analisar como as pesquisas abordaram a problemática da gestão democrática na escola paraense e como foram tratados seus temas correlatos. Os dados revelam que a gestão democrática foi pouco pesquisada pelos Programas de Pós-Graduação do Estado do Pará, ao longo do período investigado 2007 a 2017; foram identificados alguns princípios da gestão democrática nas escolas estudadas pelos autores, o que demonstra que no Estado do Pará esse processo enfrenta dificuldades para se consolidar, embora se reconheça pequenos passos e avanços na direção de uma gestão participativa, de fomento à democracia nas escolas de ensino público no Pará.

Palavras-chave: Gestão democrática; Educação Básica; Participação.

ABSTRACr This research work aimed at analyzing the principles of democratic management in Pará state schools, through the analysis of dissertations and theses, defended at post-graduation programs in Education, at public universities in the State. For the accom- 
plishment of the research, bibliographic data was collected from CAPES digital bank of dissertations and theses summaries. The collected data revealed a set of 12 dissertations and theses on democratic management, which examined the topic in Pará state schools. These dissertations and theses summaries provided subside to analyze how researchers approach the democratic management problem in the schools and its related topics. Data analysis showed that democratic management was insufficiently researched, in Education Post-graduation programs, between 2007 and 2017, in the state. The results demonstrated that, although some principles of democratic management could be identified, as well as some advances towards a more participative management, and the promotion of democracy in public schools, this process still faces difficulties to consolidate and the challenges must be faced effectively.

Keywords: Democratic management; Basic Education; Participation.

RESUMEN Este trabajo tuvo como objetivo analizar los principios de la gestión democrática en las escuelas de Pará, a partir de las disertaciones y tesis defendidas en los Programas de Posgrado en Educación de las universidades públicas de Pará. El levantamiento bibliográfica se realizó en el Banco de Tesis y Disertaciones del portal CAPES. Se identificó un conjunto de 12 trabajos de maestría y doctorado que examinan el problema de la gestión democrática en la escuela de Pará. A partir de la lectura de los resúmenes, fue posible analizar cómo la investigación abordó el tema de la gestión democrática en la escuela de Pará y cómo se trataron los temas relacionados. Los datos revelan que la gestión democrática fue poco investigada por los Programas de Posgrado del estado de Pará, durante el período investigado 2007 a 2017; se identificaron algunos principios de gestión democrática en las escuelas estudiadas por los autores, lo que demuestra que en el estado de Pará este proceso enfrenta dificultades para consolidarse, aunque reconoce pequeños pasos y avances hacia la gestión participativa, fomentando la democracia en las escuelas de educación pública en Pará.

Palabras Clave: Gestión democrática.; Educación básica; Participación.

\section{INTRODUÇÃo}

A gestão democrática no Brasil é uma conquista que em boa parte se deve à mobilização dos educadores, que historicamente vêm lutando contra qualquer forma de autoritarismo ainda presente nas escolas públicas. Esse modo de gerir a escola encontra força a partir de meados da década de 1980, com o fim do governo dos militares, na chamada redemocratização do país, e ganha força com a aprovação da Constituição Federal de 1988, que garante o direito à educação para todos e toma como princípios para a educação no país a obrigatoriedade, a gratuidade (escolas públicas), a liberdade, a igualdade e a gestão democrática. Esses princípios assegurados em lei abrem as portas para que a democracia na educação escolar se materialize.

Entende-se que a gestão democrática é mais que um princípio legal, é uma atitude, uma vez que para sua concretização necessita que o administrador de um Estado ou município possibilite condições para que seja garantida a participação da comunidade escolar nos 
aspectos de planejamento, organização, execução e avaliação dos processos administrativos e pedagógicos da escola, isto é, assegure a gestão democrática. A esse respeito, Paro (2011) se manifesta argumentando que no âmbito escolar precisa haver a democratização nas relações institucionais, para que seja promovida a partilha do poder por meio do processo de participação dos membros da comunidade escolar nas tomadas de decisões.

A concepção de gestão democrática apresentada pelo autor, de participação nas decisões tomadas no coletivo, é o que tem movido a busca pela efetivação da mesma em nossos sistemas escolares. Por entendermos que não pode haver democracia sem participação, sem respeito às diferenças, sem partilha, tomamos emprestado o conceito de gestão democrática de Paro (2011) para guiar nosso debate e discussão neste estudo.

No Estado do Pará, os princípios da gestão democrática têm sido pouco discutidos e efetivados nas escolas públicas, devido ao fato de a própria gestão dos sistemas de ensino ainda apresentarem resquícios autoritários, consequência da herança histórica da concepção de gestão que acompanhou a trajetória educacional brasileira e se intensificou a partir da década de 1960, quando os militares assumiram o poder, como é possível constatar em Oliveira (2017, p. 194), demonstrando que o autoritarismo no que concerne ao trabalho da gestão escolar é uma realidade no município de Santa Izabel do Pará, uma vez que, segundo a autora, a Lei Orgânica do Município "[...] definiu dispositivos com características autoritárias herdadas do militarismo". Ainda a esse respeito, Elias (2008, p. 19) vai além da discussão do autoritarismo na gestão escolar de Belém, e aponta indícios de atitudes da administração do município que dificultam mais ainda a realização da democracia nas instituições de ensino, pela existência da "cultura política paternalista, autoritária, excludente e clientelista tão presente e naturais no cotidiano da escola". A pesquisa de Pereira (2012) aponta que em escolas da capital do Estado do Pará há estruturas administrativas hierárquicas tradicionais ainda presentes, e dessa forma assinala nos discursos dos servidores a revelação da linha de controle severa que a gestão adota na escola Brigadeiro Fontenele, no município de Belém.

Compreendendo a gestão democrática a partir dos conceitos exibidos por Paro (2011), e entendendo que a democracia na escola é relativa e não absoluta, levantamos a seguinte questão de pesquisa: Quais princípios da Gestão Democrática estão presentes nas escolas públicas do Estado do Pará, apontadas nas teses e dissertações defendidas nos Programas de Pós-graduação das universidades paraenses?

Partindo do problema de pesquisa, traçamos o seguinte objetivo: Averiguar os princípios da gestão democrática presentes nas escolas públicas da educação básica do Estado do Pará, no período de 2007 a 2017, com base nos estudos sobre gestão democrática discutidas nos Programas de Pós-Graduação em Educação, da Universidade Federal do Pará (UFPA) e Universidade Federal do Oeste do Pará (UFOPA).

Justificamos o período de 2007 em virtude da implementação da Lei de Diretrizes e Bases da Educação Brasileira (LDB) ter sido publicada em 26 de dezembro de 1996, devendo, portanto, ter começado a ser implantada legalmente na escola a partir do ano de 2007, apesar de alguns Estados e municípios já estarem tentando implementar esse modelo de gestão. De outra maneira, consideramos que o tempo decorrido de dez anos pode ser considerado um tempo suficiente para a implementação e mobilização para a realização de 
uma ação política como a gestão democrática, por isso, procuramos estudar as discussões feitas nesses Programas de Pós-graduação em Educação acerca da gestão democrática no Estado do Pará em uma década, o que explica a escolha do ano de 2017 como recorte temporal para a investigação.

Metodologicamente, este estudo, com características de uma pesquisa qualitativa, se configurou pela coleta, organização e análise dos dados visando atender ao principal objetivo estabelecido neste estudo. Desse modo, a investigação se pautou no enfoque da pesquisa exploratório-descritivo, uma vez que, segundo Cervo (2007, p. 63), a pesquisa exploratória "[...] não requer a elaboração de hipóteses a serem testadas no trabalho, restringindo-se a definir objetivos e buscar mais informações sobre determinado assunto de estudo". E ainda, de acordo com o autor, na pesquisa descritiva as variáveis em estudo não sofrem manipulação pelo pesquisador. Assim sendo, para que se alcançassem os objetivos estabelecidos foram analisados, classificados e interpretados, sem a interferência do pesquisador, o quantitativo de 12 teses e dissertações defendidas nos PPGED da UFPA e da UFOPA.

A coleta ocorreu por meio da pesquisa documental que, de acordo com Gil (2008, p. 51), “[...], vale-se de materiais que não receberam ainda um tratamento analítico, ou que ainda podem ser reelaborados de acordo com os objetivos da pesquisa".

Foi realizado um levantamento de informações a saber: nome do programa e da instituição, ano de defesa, título da dissertação ou tese, ano de defesa, nome do autor e o enfoque sobre gestão democrática que as mesmas traziam. A plataforma utilizada para a coleta de dados foi o banco de dados da Coordenação de Aperfeiçoamento de Pessoal de Nível Superior (CAPES), especificamente no catálogo de Teses e Dissertações das instituições de ensino Superior UFPA e UFOPA. Essas informações foram coletadas e organizadas em planilha do software Excel.

A apreciação das informações coletadas tomou por base a análise de conteúdo, que ajudou a sistematizar a elaboração da planilha do software Excel para a organização dos trabalhos em uma sequência lógica de distribuição por período e palavras chaves, indicando a ordem encadeada dos trabalhos para a leitura e crítica das informações. A partir da análise dos dados foi possível responder à questão de pesquisa apresentada neste trabalho sobre gestão democrática no Estado do Pará.

Este trabalho está estruturado em três partes, sendo que na primeira parte é feita uma contextualização histórica da gestão democrática no Brasil, mostrando em que cenário se instituiu a gestão democrática nas instituições de ensino brasileiras, os principais conceitos e os ordenamentos jurídicos que a embasam. Na segunda apresentamos os resultados da análise das teses e dissertações, exibindo os aspectos da gestão democrática nelas estudadas. Na terceira parte finalizamos com nossas considerações, apontando se os objetivos deste estudo foram alcançados.

\section{CONTEXTUALIZAÇÃo histórica da GESTÃo deMocrática NO BRASIL}

Em um cenário anterior à instituição da gestão democrática observou-se a necessidade de a educação promover a formação de mão de obra, como forma de aumentar os recursos 
de capital de mercado, com vistas a melhorar a renda e a inserção de mais sujeitos na rota da produtividade do capitalismo. Nesse cenário, o paradigma que fundamentava o comando das instituições de ensino era o que se chamava de administração escolar, pautado no comando e controle, modelo de gestão influenciado pelo sistema capitalista.

A administração escolar, que foi a primeira forma de organização administrativa na educação brasileira, termo cunhado da administração de empresas, perdurou até meados da década de 1990. Com a aprovação da Lei de Diretrizes e Bases da Educação (LDB), 9394/96, esse termo foi abolido e passou a se chamar gestão escolar, inspirado na visão de democracia, cuja finalidade é democratizar o ensino brasileiro.

Dentro da perspectiva da democratização do ensino encontra-se a gestão escolar que, para Lück (2009, p. 25):

A gestão escolar constitui-se em uma estratégia de intervenção organizadora e mobilizadora, de caráter abrangente e orientada para promover mudanças e desenvolvimento dos processos educacionais, de modo que se tornem cada vez mais potentes na formação e aprendizagem dos seus alunos. Como tal, ela envolve áreas e dimensões que, em conjunto, tornam possível a realização desses objetivos.

Conforme as necessidades, as nomenclaturas e os conceitos de gestão e administração no âmbito educacional foram sendo modificados para que se ajustassem as demandas da sociedade. Por esse motivo, Lück (2006) ressalta esta ser uma temática que passou a ser considerada no âmbito das discussões educacionais a partir da década de 1990, em uma tônica conceitual do entendimento da participação do conjunto nas decisões deliberativas.

Os movimentos em favor da gestão democrática e descentralização no campo educacional começaram no início dos anos 1980, para que houvesse uma participação efetiva da comunidade escolar, não só nas eleições para diretores, mas também no planejamento da escola. Viu-se na gestão democrática uma forma de instigar a comunidade escolar a participar não só dos processos escolares, mas também da nova configuração de gestão que estava sendo empreendida, visto que, segundo Oliveira (1997), são formas mais flexíveis, em oposição ao modelo centrado nas mãos de tecnocratas.

Para adentrar mais a fundo no tema gestão democrática, é necessário entender o conceito de democracia baseado em dois princípios fundamentais: bem comum e vontade geral. Esses dois conceitos remetem ao entendimento de que a sociedade tem potencial para opinar e decidir sobre seu interesse, desse modo Schumpeter (1984, p. 313-314) diz que:

[...] o povo goza de uma opinião definida e racional sobre todas as questões que lhe são apresentadas para decidir, já que o bem comum implica respostas precisas a todas as perguntas, a ponto de todo fato e toda medida tomada ou a ser tomada poderem ser, nitidamente, classificados como bons ou ruins. Mesmo na hipótese de a administração de algum negócio público exigir aptidões e técnicas especiais que requeiram que seja ela confiada a especialistas, mesmo assim os princípios do bem comum e da vontade geral não seriam afetados, pois os especialistas simplesmente agirão de modo a realizar a vontade do povo [...]. 
Partindo do princípio de que a democracia está também pautada na partilha de poder, tomadas de decisão conjuntas e participação ativa dos envolvidos, considera-se que pode haver opiniões diversificadas do entendimento do encaminhamento das decisões, pois a compreensão de conceitos, como democracia, também é ambígua, logo os entendimentos de gestão democrática são variados, como o apresentado por Libâneo (2001, p. 7):

\begin{abstract}
A gestão democrático-participativa valoriza a participação da comunidade escolar no processo de tomada de decisão, concebe a docência como trabalho interativo e aposta na construção coletiva dos objetivos e do funcionamento da escola, por meio da dinâmica intersubjetiva, do diálogo, o consenso.
\end{abstract}

Alguns documentos marcaram de forma significativa a caminhada rumo à gestão democrática. Um dos marcos no campo da gestão educacional democrática foi o III Plano Setorial de Educação, Cultura e Desporto (III PSECD), que orientava sobre um conjunto de ações a serem desenvolvidas no período de 1980 a 1985, com base em estratégias que visam processos participativos e descentralizados no planejamento educacional.

Outro documento que também marcou a descentralização da gestão educacional foi o III Plano Nacional de Desenvolvimento (III PND), 1980-1985 que, além de várias considerações concernentes a uma gestão moderna e democrática, tinha cinco prioridades na área da educação, entre elas se destaca o planejamento participativo. Além disso, a respeito da descentralização, o Plano enfatiza:

\begin{abstract}
A ênfase nesse tema relaciona-se com a necessidade de modernizar e dar maior velocidade e eficiência ao processo de tomada de decisões em todos os campos, em benefício do desenvolvimento e do bem-estar social da população, sem prejuízo do cumprimento de regras e padrões sadios de gestão e controle das atividades governamentais (BRASIL, 1980, p. 94).
\end{abstract}

Com isso, observa-se a necessidade de participação da sociedade e comunidade escolar no que se refere ao planejamento, necessidade essa que surgiu com vistas a melhorar o índice de produtividade da educação, aumentando ou ressignificando a gestão educacional e como consequência o ensino básico, que nesse cenário objetivava de modo centralizado a formação para gerar mão de obra qualificada para o mercado de trabalho.

Ainda no que diz respeito às repercussões da implantação de gestão participativa, no I Plano Nacional de Desenvolvimento da Nova República (I PDN-NR), no período de 1986 a 1989 é apresentado de forma clara um plano de incentivo para a gestão democrática denominado "Programa de Descentralização e Participação", criado sobre o argumento de que: "Muitos dos problemas educacionais têm sua origem na excessiva centralização dos recursos públicos, na rigidez do processo decisório e na ambiguidade gerada pelas competências concorrentes na área governamental" (I PND - NR, 1986).

A respeito da garantia legal de gestão participativa citamos os artigos: 205 e 206, da Constituição Federal de 1988, que enfatizam a colaboração da sociedade no planejamento educacional e a participação na gestão, assim como a garantia de gestão democrática. Esse foi o marco que legitimou a garantia de uma gestão democrática. 
Os Planos de Desenvolvimento que priorizam a gestão democrática somam também com outros documentos que versam sobre a participação da sociedade na gestão escolar, entre eles podemos citar a Lei de Diretrizes e Bases da Educação Nacional (LDB) nº 9.394/96, no artigo 3, inciso VIII, que garante como um princípio da educação a gestão democrática do ensino público, na forma dessa Lei e da legislação dos sistemas de ensino.

E ainda a LDB em seu artigo 13, inciso VI, enfatiza que os professores deverão incumbir-se de colaborar com as atividades de articulação da escola com as famílias e com a comunidade. E no inciso II, do artigo 14, prevê a participação das comunidades escolar e local em conselhos escolares ou equivalentes.

Desse modo, compreende-se a forma como se deu o processo de implantação de estratégias e incentivo de políticas de participação social da gestão do campo educacional e os objetivos com os quais a política de gestão democrática foi instituída. Os documentos e políticas que garantem a gestão democrática são muitos e vêm sendo instituídos desde a década de 1980.

Outros temas que estão envolvidos em uma gestão democrática são: a participação da comunidade escolar nos processos escolares, os quais são entendidos como procedimentos de planejamento, execução e avaliação; e a autonomia e os conselhos escolares, ferramentas de efetivação da participação da comunidade. Pode-se considerar esses temas como indissociáveis e, se aplicados de maneira efetiva, podem resultar em uma escola autônoma e uma gestão democrática, ou mesmo, um avanço nesse caminho.

Um olhar mais crítico a respeito da gestão democrática leva a entender que muitas vezes ela pode se caracterizar em uma entrega de responsabilidade à sociedade em relação aos resultados da educação, haja vista que é esta que participa ou, pelo menos, que deveria participar de forma efetiva das tomadas de decisão e no planejamento da escola, como ressalta Gadotti (2014).

A participação da comunidade escolar na escolha da gestão educacional é apenas o primeiro passo de uma gestão participativa, integrada e aberta ao diálogo. Essa participação deve ser ampla, indo desde o momento de escolha de gestor até a participação no planejamento, no Conselho, na elaboração do PPP, em projetos e tantas outras atividades que a escola desenvolve, porém sabemos que para que isso ocorra é necessário dedicação, pois, se entende que: "a gestão democrática da escola exige, em primeiro lugar, uma mudança de mentalidade de todos os membros da comunidade escolar" (GADOTTI, 1994, p. 2).

Sendo assim, democratizar a gestão educacional não se resume à escolha de um dirigente escolar por meio de eleição direta, isso é apenas o começo de uma gestão democrática e participativa. É necessário que haja um processo de consolidação da autonomia da escola, no sentido de instigar a comunidade escolar a participar de forma ativa do planejamento, execução e avaliação. Entretanto, Lima (2006) ressalta que essa é uma atividade que por vezes se resume ao repasse de obrigações para a escola, portanto, é imprescindível a criação dos Conselhos escolares como órgãos deliberativos a fim de atender às finalidades da escola (BRASIL, 2004).

Objetivando promover a abertura ou o alargamento dos espaços democráticos na escola, Bobbio (2000) trata sobre a criação dos conselhos escolares, em que os pais se tornam representantes tendo a possibilidade de participação em algumas tomadas de decisão. Concernente à escolha de diretor escolar, essa participação da sociedade por meio de eleição direta não torna efetiva a participação da comunidade escolar e local, mas é um ponto de 
partida, que possibilita conhecer o esboço de gestão que irá assumir e representar a comunidade como um todo.

É evidente que uma gestão democrática possibilita não só a participação da comunidade escolar nos procedimentos de organização, como também outros aspectos fundamentais para o funcionamento das escolas, mas, se realizada da forma que é proposta, resultará também em uma transformação social dos indivíduos envolvidos, nesse processo, viabilizando ainda uma mudança social em nível macro.

Uma vez que o sentido mais amplo do termo democracia remete à participação da sociedade na tomada de decisões, logo assimilamos a ideia de que no contexto escolar uma gestão que seja delineada no aspecto da democracia, precisa estar aberta à comunidade. $\mathrm{E}$ embora as direções de escola, por vezes, não sejam escolhidas pelo voto direto da comunidade, mesmo assim, o princípio da democracia no que tange ao gerenciamento das instituições públicas de ensino precisa ser respeitado e preservado, visto que, a escola atende e representa uma estrutura maior que é o estado republicano.

Os órgãos da administração direta que regulamentam o processo político administrativo, e o ensino, conhecem a importância e a necessidade de estabelecer marcos que garantam as bases da democracia do país e, por isso, sabem que a escola é um dos lugares necessários e ideais para que sejam iniciadas as atividades afins da promoção da participação, do diálogo, das decisões compartilhadas, ou seja, das ações afins daquilo que deve ocorrer no modo de governo republicano. Por isso, todas as normativas promulgadas pelas instâncias da administração pública são norteadas para esse princípio, como acontece no Plano Nacional de Educação (PNE) que, em sua última versão de 2014 a 2024, por meio da Meta 19, determinou: "assegurar condições, no prazo de 2 (dois) anos, para a efetivação da gestão democrática da educação, associada a critérios técnicos de mérito e desempenho e à consulta pública à comunidade escolar, no âmbito das escolas públicas [...]”' (BRASIL, 2014, p. 315).

Na mesma direção do atendimento da demanda dos princípios democráticos que norteiam o funcionamento da república, o Estado do Pará também promulgou leis como o Plano Estadual de Educação (PEE), dando seguimento ao proposto no PNE de 2014-2024, no que diz respeito à participação democrática por meio da constituição de gestões escolares descentralizadas, e como está estabelecido no Pará (2015, p. 32), "promoção do princípio da gestão democrática da educação pública" no intuito de garantir a participação do Estado na cooperação técnica, de disponibilização de recursos, financiamento e a própria abertura para presença da comunidade escolar nas decisões das instituições de ensino.

\section{A experiência de gestão democrática no eStado do Pará: o QUE ReVe- LAM AS PRODUÇÕES ACADÊMICAS}

Na pesquisa realizada no Catálogo de Teses e Dissertações da CAPES, com o intuito de verificar os trabalhos feitos no Estado do Pará sobre Gestão Democrática, foram identificadas apenas duas IEFS do Estado do Pará (UFOPA e UFPA) que, em seu Programa de Pós-graduação, possuem teses e ou dissertações defendidas, no período de 2007 a 2017 , com a temática pesquisada. Para a realização de busca no catálogo da CAPES, foi usado como termo as palavras: "gestão democrática UFOPA" e "gestão democrática UFPA". Além disso, foi utilizado o filtro de Programas de Pós-Graduação em Educação.

Nessa busca realizada foram encontrados 12 trabalhos defendidos no período de 2005 a 2017, sendo que destes, dez são dissertações e dois são teses, o que revela a pouca produção sobre gestão democrática nos Programas de Pós-Graduação em Educação, no Estado do Pará. 
A seguir, exibimos os trabalhos que foram analisados, destacando o título do trabalho, autor, ano, IESF, nível do programa e ênfase da pesquisa, a última com o objetivo de verificar qual a ênfase de discussão de cada um, para então posteriormente discorrer sobre os aspectos principais e resultados presentes nos trabalhos elencados no Quadro 1 (anexo).

\section{Quadro 1 - Trabalhos Analisados de Programa de Pós-Graduação em Educação.}

\begin{tabular}{|c|c|c|c|c|c|}
\hline Obra/Título & Autor & Ano & IES & Nível & Ênfase da pesquisa \\
\hline $\begin{array}{l}\text { A Democratização da gestão escolar no } \\
\text { município de Santa Bárbara do Pará, a partir } \\
\text { do PDE }\end{array}$ & $\begin{array}{l}\text { CASTRO, } \\
\text { Maria Rosana de } \\
\text { Oliveira }\end{array}$ & 2007 & $\begin{array}{l}\text { PPGE/ } \\
\text { UFPA }\end{array}$ & Mestrado & $\begin{array}{l}\text { Enfatiza a importância da autonomia } \\
\text { e da participação na escola pública } \\
\text { como meio para alcançar a qualidade } \\
\text { desejável na educação. }\end{array}$ \\
\hline $\begin{array}{l}\text { O Conselho Municipal de Educação: } \\
\text { a participação da sociedade civil e os } \\
\text { desafios da representação democrática nas } \\
\text { deliberações das políticas educacionais para } \\
\text { o município de Belém/PA }\end{array}$ & $\begin{array}{l}\text { ELIAS, Lina } \\
\text { Gláucia Dantas }\end{array}$ & 2008 & $\begin{array}{l}\text { PPGE/ } \\
\text { UFPA }\end{array}$ & Mestrado & $\begin{array}{l}\text { Os conselhos de educação como } \\
\text { alternativa de ampliação da } \\
\text { participação da sociedade civil no } \\
\text { exercício da cidadania. }\end{array}$ \\
\hline $\begin{array}{l}\text { Implicações do Terceiro Setor no Debate da } \\
\text { Gestão Democrática: um estudo a partir do } \\
\text { programa "Amigos na Escola" }\end{array}$ & $\begin{array}{l}\text { GARCIA, } \\
\text { Maurício Luis } \\
\text { Silva }\end{array}$ & 2009 & $\begin{array}{l}\text { PPGE/ } \\
\text { UFPA }\end{array}$ & Mestrado & $\begin{array}{l}\text { Incentivo à participação da } \\
\text { comunidade na gestão escolar como } \\
\text { um instrumento de democratização } \\
\text { da gestão. }\end{array}$ \\
\hline $\begin{array}{l}\text { O CME do Município de Ananindeua na } \\
\text { Construção da Política Educacional: a busca } \\
\text { pela participação social }\end{array}$ & $\begin{array}{l}\text { FARIAS, Maria } \\
\text { Celeste Gomes de }\end{array}$ & 2009 & $\begin{array}{l}\text { PPGE/ } \\
\text { UFPA }\end{array}$ & Mestrado & $\begin{array}{l}\text { Participação da sociedade civil } \\
\text { organizada no CME como uma } \\
\text { tentativa de construir uma política } \\
\text { educacional com base nos princípios } \\
\text { da democracia. }\end{array}$ \\
\hline $\begin{array}{l}\text { O PDDE como Instrumento de } \\
\text { Democratização da Gestão Escolar no Pará }\end{array}$ & $\begin{array}{l}\text { CARDOSO, José } \\
\text { Carlos Martins }\end{array}$ & 2009 & $\begin{array}{l}\text { PPGE/ } \\
\text { UFPA }\end{array}$ & Mestrado & $\begin{array}{l}\text { Processo de democratização da gestão } \\
\text { escolar, autonomia e participação da } \\
\text { comunidade escolar. }\end{array}$ \\
\hline $\begin{array}{l}\text { Eleição Direta para Diretor Escolar: desafio à } \\
\text { democratização da gestão }\end{array}$ & $\begin{array}{l}\text { PEREIRA, } \\
\text { Lucenil da Rocha }\end{array}$ & 2012 & $\begin{array}{l}\text { PPGE/ } \\
\text { UFPA }\end{array}$ & Mestrado & $\begin{array}{l}\text { Eleição Direta para diretor escolar } \\
\text { na perspectiva da democratização da } \\
\text { gestão e da autonomia escolar. }\end{array}$ \\
\hline $\begin{array}{l}\text { Institucionalização da Gestão Democrática } \\
\text { da Educação como Política Pública no } \\
\text { Sistema Municipal de Ensino De Igarapé- } \\
\text { Açu, Pará }\end{array}$ & $\begin{array}{l}\text { PAZ, Vanilson } \\
\text { Oliveira }\end{array}$ & 2015 & $\begin{array}{l}\mathrm{PPGE} / \\
\mathrm{UFPA}\end{array}$ & Doutorado & $\begin{array}{l}\text { Gestão democrática, participação e } \\
\text { autonomia escolar. }\end{array}$ \\
\hline $\begin{array}{l}\text { O Plano de Ações Articuladas e a Gestão } \\
\text { Educacional e o Município de Altamira-Pará }\end{array}$ & $\begin{array}{l}\text { SOUSA, } \\
\text { Raimundo }\end{array}$ & 2015 & $\begin{array}{l}\text { PPGE/ } \\
\text { UFPA }\end{array}$ & Mestrado & $\begin{array}{l}\text { Implementação do PAR e } \\
\text { democratização da gestão educacional. }\end{array}$ \\
\hline $\begin{array}{l}\text { O Plano de Ações Articuladas e suas } \\
\text { Implicações para a Gestão da Rede } \\
\text { Municipal de Educação De Barcarena-PA }\end{array}$ & $\begin{array}{l}\text { CAMARGO, } \\
\text { Maria Dayse } \\
\text { Henriques De }\end{array}$ & 2017 & $\begin{array}{l}\text { PPGE/ } \\
\text { UFPA }\end{array}$ & Mestrado & $\begin{array}{l}\text { Gestão democrática, descentralização } \\
\text { do poder, participação coletiva e } \\
\text { autonomia das instituições }\end{array}$ \\
\hline $\begin{array}{l}\text { Implicações do Plano de Ações Articuladas } \\
\text { na Gestão Escolar do Município de Belém }\end{array}$ & $\begin{array}{l}\text { Moraes, Valeria } \\
\text { Silva de }\end{array}$ & 2017 & $\begin{array}{l}\text { PPGE/ } \\
\text { UFPA }\end{array}$ & Doutorado & $\begin{array}{l}\text { Gestão democrática, eleição para } \\
\text { diretores, Conselhos Escolares e } \\
\text { participação na elaboração do PPP. }\end{array}$ \\
\hline $\begin{array}{l}\text { O Instituto das Eleições Diretas para } \\
\text { Diretor de Escolas Municipais da Região } \\
\text { Metropolitana de Belém }\end{array}$ & $\begin{array}{l}\text { OLIVEIRA, } \\
\text { Patricia Soraya } \\
\text { Cascaes Brito de }\end{array}$ & 2017 & $\begin{array}{l}\text { PPGE/ } \\
\text { UFPA }\end{array}$ & Mestrado & $\begin{array}{l}\text { Eleições diretas e democratização da } \\
\text { escola pública. }\end{array}$ \\
\hline $\begin{array}{l}\text { Coordenação Pedagógica: Contradições e } \\
\text { Possibilidades para a Construção da Gestão } \\
\text { Democrática na Escola }\end{array}$ & $\begin{array}{l}\text { ARRUDA, } \\
\text { Elenise Pinto de }\end{array}$ & 2015 & $\begin{array}{l}\text { PPGE/ } \\
\text { UFOPA }\end{array}$ & Mestrado & $\begin{array}{l}\text { Gestão democrática e as práticas de } \\
\text { coordenadores pedagógicos. }\end{array}$ \\
\hline
\end{tabular}

Fonte: Quadro construído a partir dos dados do banco de dissertações e teses da CAPES (2018). 
O Quadro 1 apresenta um panorama geral dos trabalhos e das temáticas sobre gestão democrática produzidos no âmbito dos PPGE das duas instituições. Identifica-se que todas as produções de forma direta ou indireta discutem o tema Gestão Democrática. Aquelas produções que não trazem em seu título a palavra "gestão democrática", de certa forma discutem a temática porque seu objeto está relacionado a um dos princípios da gestão democrática, estipulado pela LDB n ${ }^{\circ}$. 9.394/96, como: autonomia, participação, democratização, eleições diretas para direção escolar, Conselhos escolares e Projeto Político Pedagógico.

De certa forma, esses temas estão intrinsecamente ligados e, geralmente, aparecem juntos na mesma obra, mas com ênfase em algum tema específico, pois fazem parte do processo de democratização da escola. Cada tema com sua definição ou conceituação, mas com um só objetivo, que é verificar a efetivação da gestão democrática nas instituições públicas de ensino.

Cada trabalho teve um foco de investigação, porém é possível perceber que todos buscavam compreender o princípio da gestão democrática na realidade da escola pesquisada e como essa se constitui discutindo os instrumentos que fazem parte desse processo, como, por exemplo, a construção coletiva de um PPP, as eleições diretas, a participação da comunidade escolar nas tomadas de decisão e construção da transformação da escola em um espaço democrático, os conselhos escolares como alternativa para a efetivação e a participação social nas instituições.

Os trabalhos analisados também investigaram programas e estratégias do governo e sua influência e implicações na gestão democrática, como exemplo: Amigos da Escola, Plano de Ações Articuladas, Plano de Desenvolvimento da Educação e Programa Dinheiro Direto na Escola. Alguns trabalhos buscaram verificar de que forma essas estratégias/programas contribuem ou não para gestão participativa.

Dos doze trabalhos, três trataram de Conselhos Municipais de Educação e Conselhos Escolares, três do Plano de Ações Articuladas, dois de Eleições Diretas para diretores escolares, um do PDE, um do PDDE, um da Institucionalização da gestão democrática e um sobre as práticas da coordenação pedagógica. Apesar de cada um abordar um dos princípios da gestão democrática, todos tinham a mesma finalidade, verificar as implicações na gestão participativa, bem como, sua efetivação na gestão educacional. A diversidade de abordagens de temas e sua influência para a efetivação de uma gestão participativa possibilitou uma visão geral de como se constitui a gestão democrática nas concepções observadas.

Dos 12 trabalhos analisados, apenas um apresentou de forma mais consolidada elementos democráticos relacionados a uma gestão participativa, mas não em sua completude, ou seja, nem todos os princípios que envolvem uma gestão democrática são contemplados, visto que, apenas uma eleição direta não garante uma gestão que incentiva a participação da comunidade escolar, ou existe a participação da comunidade escolar, mas não há uma autonomia da instituição de ensino, ou ainda, como conclui uma das autoras, cuja pesquisa foi analisada:

A luta pelo processo de democratização da sociedade não é algo dado ou herdado, mas uma conquista, um processo lento e persistente que precisa muito mais que a institucionalização em leis, é necessário que o cidadão tome consciência que sua participação no espaço público é fundamental para exigir do Estado o 
cumprimento de seus deveres em matéria de serviços públicos essenciais aos cidadãos, e a educação é um desses direitos que deve ser garantido (CASTRO, 2007, p. 119).

Os outros onze trabalhos, que representam 91,66\%, apresentaram resultados muito parecidos, o que acaba por caracterizar a maioria das instituições de ensino do Pará, no que diz respeito à efetivação da gestão democrática, já que os trabalhos analisados foram feitos em municípios e regiões distintas. Ressalta-se que a intenção não é generalizar, mas exibir qual concepção de gestão democrática aparece com mais força nas escolas paraenses, segundo as teses e dissertações observadas.

As teses e dissertações analisadas, de maneira geral, apontaram que existe nas escolas, por elas estudadas, uma fragilidade nos processos de democratização da gestão nas escolas paraenses, tendo em vista a centralidade do poder decisório ainda presente, com aspectos de uma gestão gerencial e patrimonial, com vistas a fortalecer o sistema capitalista. Os elementos que levam a essa compreensão é o fato de se perceber na leitura dos documentos analisados que, na maioria dos estudos, as(os) pesquisadoras(es) encontraram falta de oportunidade de participação da comunidade escolar nas tomadas de decisões da escola, como elaboração e discussão conjunta no PPP, momentos de discussão e planejamento das atividades pedagógicas a serem desenvolvidas na escola, falta de participação dos pais em reuniões e/ou projetos que os envolva na escola, participação ativa nos Conselhos Escolares.

Os trabalhos realizados com ênfase nos Conselhos Municipais de Educação e Conselho Escolar revelaram que há uma falta de autonomia financeira e administrativa e que é difícil manter a frequente participação dos conselheiros. Além disso, os estudos apontam que alguns conselheiros municipais são escolhidos por indicação do prefeito. Essa mesma situação se repete na escola, em que a gestão escolar tem influência direta na escolha dos conselheiros. Esse controle das gestões sobre os conselhos compromete a democratização no sistema de ensino.

Os resultados dos trabalhos que abordaram a temática das eleições diretas para diretor escolar mostraram que a escolha de diretor por meio de eleições diretas não garante a democratização da gestão, uma vez que a eleição direta é só um instrumento de incentivo à gestão participativa, levando em consideração que após a escolha de um gestor é necessário que haja a participação da comunidade escolar nos processos posteriores, como Conselho Escolar, elaboração conjunta do PPP da instituição e outros aspectos que necessitam de tomadas de decisão coletiva. Além disso, uma gestão centralizada na figura do diretor com práticas autoritárias de gestão é um aspecto presente nas realidades pesquisadas.

Sobre as pesquisas realizadas com ênfase no plano de Ações Articuladas (PAR), observou-se que essa estratégia pouco contribuiu com a efetivação da gestão participativa, embora seja um instrumento para tal.

Um dos trabalhos que apresentaram de forma mais consolidada uma gestão com indicadores democráticos foi a pesquisa realizada sobre as práticas da coordenação pedagógica para a efetivação da gestão democrática intitulado COORDENAÇÃ̃ PEDAGÓGICA: CONTRADIÇÕES E POSSIBILIDADES PARA A CONSTRUÇÃO DA GESTÃO DEMOCRÁTICA NA ESCOLA, cuja autora é Elenise Pinto de Arruda, 2015. Na análise da obra, foram identificados elementos democráticos com perfil participativo, como eleição 
direta para diretor, conselhos escolares com participação ativa da sociedade e elaboração conjunta do PPP da instituição. Percebeu-se também que para que se destaquem esses elementos há um tremendo esforço da coordenação pedagógica, fazendo que o compromisso envolvido nas atividades gere o resultado positivo.

Os demais trabalhos, que trataram de questões como programas do governo (Amigos da PDE, PDDE) influenciam na gestão democrática, tiveram resultados não muito diferentes das análises anteriores, ou seja, mesmo com programas e estratégias ainda é muito difícil a efetivação de uma gestão participativa voltada para o incentivo à democracia.

Os desafios para a efetivação da democratização escolar são muitos, entre eles a prevalência de uma estrutura hierárquica tradicional, problemas democráticos em relação aos recursos financeiros recebidos pela escola, professores que não se articulam ou que não estão dispostos a uma organização integrada para efetivar a construção coletiva de um PPP, mas para sua execução também de maneira coletiva.

Além disso, outro fator relevante e talvez o que mais dificulta uma gestão democrática é a falta de formação específica para gestores escolares e para a comunidade escolar como um todo, uma formação que apresente os aspectos legais e reais de como se alcançar uma gestão participativa, mostrando os resultados positivos que esta pode trazer para uma instituição pública de ensino.

A centralidade do poder decisório pelo governo, práticas autoritárias, escolhas de direção escolar por meio de indicação política e PPP elaborado somente com a participação da coordenação pedagógica, ainda são aspectos comumente encontrados nas escolas em que foram feitas as pesquisas, além do prevalecimento de modelos de gestão pautados nos aspectos gerencial e patrimonial.

\section{CONSIDERAÇões FINAIS}

As discussões conceituais e historiográfica sobre a concretização da experiência de gestão democrática nas escolas, que vêm sendo implementadas no país nos dez anos em que concentramos a pesquisa, nos possibilitaram perceber que esse modelo de gestão ainda está em processo de consolidação, e devido às interferências políticas da administração pública e seus agentes, faz a escola se tornar um ambiente desinteressado de construções políticas que conduzam à participação da comunidade. Os dados da pesquisa nos levam a entender que nas escolas paraenses, foco de nossa investigação, ainda vai demorar para efetivar um trabalho de gestão democrática.

Contudo, essa fragilidade é o resultado da forma como a sociedade na atualidade encara o que significa democracia e a criação de canais que garantam sua efetivação, o que também pode ser notado na ínfima quantidade de pesquisas dedicadas ao tema em questão nos programas de pós-graduação em educação de todo o Estado do Pará. Isso pode refletir que o tema da gestão democrática, mesmo em um seguimento pós-superior, é tido como uma discussão desprovida de grande significância acadêmica, por isso, precisamos discutir mais sobre o assunto para que outros pesquisadores se sintam motivados e preocupados em tratar da questão e com isso mobilizar a comunidade acadêmica, os órgãos que fomentam 
a pesquisa no país, os Programas de Pós-Graduação em Educação, a sociedade, a própria escola em querer promover gestão democrática.

A democratização da escola pública ainda é um feito muito distante quanto a sua universalização e até mesmo quanto a sua garantia nas escolas de ensino público. Contudo, como estímulo pode se afirmar que quando se tem uma gestão democrática efetiva nas escolas públicas é possível verificar resultados exitosos, uma vez que a comunidade acompanha e fiscaliza a materialização das políticas a serem feitas diretamente pelas ações desenvolvidas pela gestão. Mas, tais resultados positivos só serão alcançados se pensados em conjunto, mediante a participação da comunidade da escola, sendo isso um fato que realmente torna a escola o que ela deve ser, um espaço de transformação social e construção coletiva do saber.

A questão da pesquisa foi respondida quando se constatou nas produções analisadas que há pouco esforço na efetivação da gestão democrática nas escolas paraenses, no que pese às estratégias e aos incentivos do governo para implantar esse princípio previsto na legislação educacional. Ficou evidenciado, ainda, que as escolas possuem um ou outro princípio de gestão democrática, e o mais presente é a escolha de diretores, apesar desse aspecto não significar a democratização na escola de educação básica. As concepções de gestão democrática que puderam ser visualizadas com a pesquisa ainda estão muito distantes do que é previsto nos documentos oficiais.

Mesmo com os pequenos avanços rumo a uma gestão participativa, os trabalhos ainda levantaram outra questão que cabe ser refletida: os avanços gerados seriam de fato para oportunizar a participação coletiva e incentivar a democracia ou apenas para descentralizar as responsabilidades da gestão?

Apesar das dificuldades e desafios encontrados na institucionalização de uma gestão que seja de fato democrática, mediante a análise apresentada é possível perceber pequenos passos e avanços vagarosos na direção de uma gestão participativa, de fomento à democracia nas escolas de ensino público no Pará. Porém, mesmo que de forma mitigada, é importante que haja gradativamente uma mudança nos modelos de gestão atuais para que seja possível uma educação de qualidade que não sirva aos interesses do capital, mas sim às reais necessidades da sociedade. É necessário ainda que haja por parte das Secretarias de Educação dos municípios paraenses maior empenho e fomento para a efetivação da gestão democrática, fazendo valer o que é garantido na legislação constitucional e educacional brasileira.

\section{REFERÊNCIAS}

AGUIAR, M. Â. S.; FERREIRA, N. S. C. Gestão da educação: impasses, perspectivas e compromissos, 7. ed. São Paulo/SP: Cortez, 2009.

ARRUDA, E. P. Coordenação pedagógica: contradições e possibilidades para a construção da gestão democrática na escola. Dissertação (Mestrado) Programa de Pós-Graduação em Educação da Universidade Federal do Oeste do Pará. Santarém, 2015. 
BOBBIO, N. O futuro da democracia. São Paulo: Paz e Terra, 2000.

BRASIL. Conselho Escolar: processos, mobilização, formação e tecnologia. Fortaleza, 2013. Disponível em: http://portal.mec.gov.br/index.php?option=com_docman\&view=download\&alias=43181-livro-ufc-conselho-escolar-pdf-1\&category_slug=junho-2016-pdf\&Itemid=30192. Acesso em: 20/03/2019

BRASIL. III Plano Nacional de Desenvolvimento, 1980/85.

BRASIL. III Plano Setorial de Educação, Cultura e Desporto (1980/85). Brasília, 1980.

BRASIL. Instituto Nacional de Estudos e Pesquisas Educacionais Anísio Teixeira. Plano Nacional de Educação PNE 2014-2024: Linha de Base. Brasília, DF: Inep, 2015.

BRASIL. Ministério da Educação. Secretaria de Educação Básica. Conselhos Escolares: democratização da escola e construção da cidadania. Programa Nacional de Fortalecimento dos Conselhos Escolares, v. 1. Brasília: MEC, SEB, 2004.

CAMARGO, M. D. H. O plano de ações articuladas e suas implicações para a gestão da rede municipal de educação de Barcarena-PA. Dissertação (Mestrado) - Programa de Pós-Graduação em Educação - Universidade Federal do Pará, Instituto de Ciências da Educação, Belém, 2017.

CARDOSO, J. C. M. O PDDE como instrumento de democratização da gestão escolar no Pará. Dissertação (Mestrado) Programa de Pós-graduação em Educação - Universidade Federal do Pará, Instituto de Ciências da Educação, Belém, 2009.

CASTRO, M. R. de O. A democratização da gestão escolar no município de Santa Bárbara do Pará a partir do PDE. Dissertação. Mestrado Acadêmico em Educação - Programa de Pós-Graduação em Educação, Universidade Federal do Pará. Belém/PA, 2007.

CASTRO, M. R. de O. A democratização da gestão escolar no município de Santa Bárbara do Pará a partir do PDE. Dissertação (Mestrado) Programa de Pós-Graduação em Educação - Universidade Federal do Pará, Centro de Educação, Belém, 2007.

CERVO, A. L.; BERVIAN, P. A.; SILVA, Roberto da. Metodologia científica, 6. ed. São Paulo: Pearson Prentice Hall, 2007.

DALVA, G.; SOUZA, A. L. L. de. A política educacional brasileira com foco na gestão descentralizada: uma estratégia para a participação e autonomia da gestão escolar, XXIV Simpósio Brasileiro/III Congresso Interamericano de Política e Administração da Educação, 2009. Disponível em: http://www.anpae.org.br/congressos_antigos/simposio2009/125b.pdf. Acesso em: 23 mar. 2018. 
ELIAS, L. G. D. O Conselho Municipal de Educação: a participação da sociedade civil e os desafios da representação democrática nas deliberações das políticas educacionais para o município de Belém (Mestrado). Instituto de Ciências da Educação. Programa de Pós-Graduação em Educação, Linha de Pesquisa Políticas Públicas Educacionais. Universidade Federal do Pará. Belém, 2008

FARIAS, M. C. G. O CME do município de Ananindeua na construção da política educacional: a busca pela participação social. Dissertação (Mestrado) - Programa de Pós-Graduação em Educação - Universidade Federal do Pará, Instituto de Ciências da Educação, Belém, 2009.

FERREIRA, N. S. C. Gestão democrática da educação: atuais tendências, novos desafios. São Paulo: Cortez, 2008.

FERREIRA, N. S. C. Políticas públicas e gestão da educação: polêmicas, fundamentos e análises, 2. ed. Brasília-DF, 2011.

FONSECA, J. J. S. Metodologia da pesquisa científica. Fortaleza: UEC, 2002. Apostila. GADOTTI, M. Gestão Democrática com Participação Popular: No Planejamento e na organização da educação nacional. Disponível em: http:/conae2014.mec.gov.br/images/ pdf/artigogadotti_final.pdf. Acesso em: 23 mar. 2018.

GADOTTI, M. Gestão Democrática e Qualidade de Ensino, $1^{\circ}$. Fórum Nacional Desafio da Qualidade Total no Ensino Público. Belo Horizonte, jul. 1994.

GARCIA, M. L. S. Implicações do terceiro setor no debate da gestão democrática: um estudo a partir do programa "Amigos da Escola". Dissertação (Mestrado) Programa de Pós-Graduação em Educação - Universidade Federal do Pará, Instituto de Ciências da Educação, Belém, 2009.

GIL, A. C. Métodos e técnicas de pesquisa social, 6. ed. São Paulo: Atlas, 2008.

LIBÂNEO, J. C. Democratização da escola pública: a pedagogia crítico-social dos conteúdos, 17. ed. São Paulo/SP, 2001.

LIMA, L. Administração da Educação e autonomia das Escolas. In: Sociedade Portuguesa de Ciências da Educação, e, A Educação em Portugal (1996-2006). Alguns contributos de Investigação. Lisboa: Conselho Nacional de Educação, 2006.

LUCK, H. A gestão participativa na escola, 9. ed. Petrópolis: Vozes, 2006.

LÜCK, H. Dimensões de gestão escolar e suas competências. Curitiba: Positivo, 2009. 
NOVAIS, V. da S. de M. Implicações do Plano de Ações Articuladas na gestão escolar do município de Belém. Tese (Doutorado) Programa de Pós-Graduação em Educação Universidade Federal do Pará, Instituto de Ciências da Educação, Belém, 2017.

OLIVEIRA, D. A. de O. Gestão Democrática da Educação: desafios contemporâneos. Petrópolis-RJ: Vozes, 1997.

OLIVEIRA, P. S. C. B. O instituto das eleições diretas para diretor em escolas municipais da região metropolitana de Belém. Dissertação (Mestrado). Instituto de Ciências da Educação. Programa de Pós-Graduação em Educação, Linha de Pesquisa Políticas Públicas Educacionais. Universidade Federal do Pará. Belém, 2017.

PARÁ. S. R. O. J. LEI Nº 8.186, DE 23 DE JUNHO DE 2015. Aprova o Plano Estadual de Educação - PEE e dá outras providências. Diário Oficial. República Federativa do Brasil - Estado do Pará. Belém: Imprensa Oficial do Estado, 2015. ANO CXXV DA IOE, 125․ DA REPÚBLICA No . 32.913. Disponível em: http://fne.mec.gov.br/images/PEE/PAPEE.pdf. Acesso em: 01/10/2019.

PARO, V. H. Administração Escolar, 9. ed. São Paulo/SP: Cortez, 2000.

PARO, V. H. Crítica da Estrutura da Escola, 1. ed. São Paulo: Cortez, 2011.

PAZ, V. O. Institucionalização da gestão democrática da educação como política pública no Sistema Municipal de Ensino de Igarapé-Açu, Pará. Tese (Doutorado) Programa de Pós-Graduação em Educação - Universidade Federal do Pará, Instituto de Ciências da Educação, Belém, 2015.

PEREIRA, L. da R. Eleição direta para diretor escolar: desafio à democratização da gestão (Mestrado). Instituto de Ciências da Educação. Programa de Pós-Graduação em Educação, Linha de Pesquisa Políticas Públicas Educacionais. Universidade Federal do Pará. Belém, 2012.

PERONI, V. Política educacional e papel do Estado: no Brasil dos anos 1990. São Paulo/ SP: Xamã, 2003.

SCHUMPETER, J. A. Capitalismo, socialismo e democracia. Rio de Janeiro: J. Zahar, 1984.

SOUSA, R. O plano de ações articuladas e a gestão educacional do município de Altamira-Pará. Dissertação (Mestrado) Programa de Pós-Graduação em Educação - Universidade Federal do Pará, Instituto de Ciências da Educação, Belém, 2015. 


\section{DADOS DOS AUTORES:}

\section{Larissa Moura Lisboa Becker}

Graduada em Pedagogia. Especialista em Políticas educacionais pela Universidade Federal do Pará/PA-Brasil larissamoura95@gmail.com

\section{Maria de Fátima Matos de Souza}

Pós-doutoramento pela Universidade Católica de Brasília- Brasil. Professora da Universidade Federal do Pará/PA-Brasil. fmatoz@ufpa.br

\section{Renato Pinheiro da Costa}

Doutorado em Educação. Professor do Programa de Pós-Graduação da Universidade Federal do Pará/PA-Brasil renatopc@ufpa.br

Submetido em: 4-2-2020

Aceito em: 7-12-2020 